\title{
Highly Efficient MicroRNA Delivery Using Functionalized Carbon Dots for Enhanced Conversion of Fibroblasts to Cardiomyocytes
}

\section{Lei Yang \\ Song Xue \\ Mingjun Du \\ Feng Lian}

Department of Cardiovascular Surgery, Renji Hospital, School of Medicine, Shanghai Jiao Tong University, Shanghai, 200127, People's Republic of China
Correspondence: Feng Lian

Email dr.lianfeng@hotmail.com
Introduction: The reprogramming of induced cardiomyocytes (iCMs) is of particular significance in regenerative medicine; however, it remains a great challenge to fabricate an efficient and safe gene delivery system to induce reprogramming of iCMs for therapeutic applications in heart injury. Here, we report branched polyethyleneimine (BP) coated nitrogen-enriched carbon dots (BP-NCDs) as highly efficient nanocarriers loaded with microRNAs-combo (BP-NCDs/MC) for cardiac reprogramming.

Methods: The BP-NCDs nanocarriers were prepared and characterized by several analytical techniques.

Results: The BP-NCDs nanocarriers showed good microRNAs-combo binding affinity, negligible cytotoxicity, and long-term microRNAs expression. Importantly, BP-NCDs/MC nanocomplexes led to the efficient direct reprogramming of fibroblasts into iCMs without genomic integration and resulting in effective recovery of cardiac function after myocardial infarction (MI).

Conclusion: This study offers a novel strategy to provide safe and effective microRNAsdelivery nanoplatforms based on carbon dots for promising cardiac regeneration and disease therapy.

Keywords: nitrogen-enriched carbon dots, branched polyethyleneimine, microRNAs, direct reprogramming, induced cardiomyocytes

\section{Introduction}

Heart failure, one of the most feared health conditions in humans, is attributed to hindered regenerative capability in cardiomyocytes and an impaired heart function. $^{1,2}$ Inadequate regeneration of cardiomyocytes and excessive fibrosis are among the most familiar reasons for heart failure since this leads to substantial damage of tissue structure and function. In recent years, cell-based therapies, or the introduction of healthy cells into cardiac scar tissue, have modestly improved various measures of cardiac function, which has made major advances in cardiac regenerative medicine. ${ }^{3-5}$ However, concerns about the maturity and functional heterogeneity of stem cell-derived cardiomyocytes, the low survival, and retention of delivered cells, as well as their potential tumorigenicity still exist. ${ }^{6-8}$ To address $^{6}$ these limitations, the reprogramming of induced-cardiomyocytes (iCMs) derived from abundant non-cardiomyocytes has been gaining tremendous attention as a novel therapy for cardiac diseases. ${ }^{9-11}$ Since the first reported three cardiaclineage-related transcription factors, namely Gata4, Mef2c, and Tbx5 (GMT), ${ }^{12-14}$ 
different combinations of transcription factors and small molecules have also been identified to improve the effectiveness of cardiomyocyte reprogramming. ${ }^{15-18}$

An emerging therapeutic option for direct reprogramming of cardiac fibroblasts to cardiomyocytes involves microRNAs (miRNAs). miRNAs play an essential role in regulating biological processes, including controlling gene transcription through the activation or degradation of targeted mRNA. Some preeminent works have demonstrated miRNAs-combo as highly efficient reprogramming tools. For instance, Jayawardena et al provided proof-of-concept that miRNAs have the capability of directly converting fibroblasts to a cardiomyocyte-like phenotype in vitro and cardiac reprogramming in vivo. ${ }^{22}$ The repressive actions of miRNAs on gene expression can be powerful as a single miRNA may target multiple pathways simultaneously. ${ }^{19-21}$ Chemically synthesized miRNAs mimics are easily administered to cells via lipid-based transfection and exhibit low toxicity in experiments. ${ }^{22,23}$ Moreover, small size of a single miRNA allows the packing of multiple transcripts in the same delivery vector to increase reprogramming efficiency and functional homogeneity of reprogrammed cells. ${ }^{24}$ However, administering naked miRNAs is difficult based on its surface charge (negatively charged) and potential rapid degradation. Therefore, highly efficient and biocompatible vehicles are necessary to protect and deliver miRNAs into targeted cells.

Viruses (eg, retroviruses, and lentiviruses) and liposomes have been widely studied as gene vectors to convert fibroblasts to cardiomyocytes directly. ${ }^{4,12,15,22,25}$ However, disadvantages such as genotoxic transgene integration and the ability to trigger immune responses, which may lead to insertable mutations and tumor formation, have prevented its therapeutic potential. ${ }^{26}$ Thus, novel non-viral reprogramming systems are required to allow the clinical application of cardiac reprogramming. ${ }^{24,27-31}$ Non-viral vector systems including cationic lipids, cationic polymers, dendrimers, and peptides have shown good biocompatibility and the potential for systemic gene delivery. ${ }^{32-35}$ Artificial cationic polymers PEI with an MW of $25 \mathrm{kDa}$ is acknowledged as the "gold standard" of polymeric gene vectors for its excellent gene transfection efficiency and universality. Although the higher charge density of cationic polymers PEI provides strong nucleic acid binding ability, these polyplexes are confronted with the problem of cytotoxicity. $^{36}$ These barriers have motivated researchers to find new strategies to promote the performance of non- viral gene vectors, and simultaneously allow the materials to be multifunctional to meet disease therapy requirements.

Carbon dots (CDs) have drawn intensive interest in the nanotechnology field due to their high water solubility, favorable photoluminescence property, good chemical stability, multifunctional surface functions, and low cytotoxicity. $^{37-42}$ To explore their delivering capability for potential therapy, much work has been focused on the surface modification of CDs with biocompatible ligands (ie, biomacromolecules, peptides, antibodies, etc.). ${ }^{43-45}$ Although CDs have been successfully studied in biosensor, cell imaging, and recognition fields, their applications as non-viral vectors with directly transformed reprogramming factors have rarely been reported.

Herein, we designed branched polyethyleneimine modified N-enriched CDs (BP-NCDs) with low toxicity for use as a non-viral vector. Then, loaded BP-NCDs with miRNAs-combo via electrostatic interactions to form targeted nanocomplexes (BP-NCDs/MC). We found that reprogramming fibroblasts into iCMs using BP-NCDs /MC nanocomplexes resulted in a significant upregulation of cardiomyocyte genes and a gradual inhibition of fibroblast genes. Furthermore, local injection of BP-NCDs/MC nanocomplexes into mouse hearts significantly improved cardiac function after myocardial infarction (Figure 1). This study not only shows the versatility of BP-NCDs /MC nanocomplexes as delivery vectors to directly reprogram fibroblasts into iCMs without genomic integration but also offers inspiration for the exploration of applications of CD-based gene/drug delivery systems in cardiac injury treatment.

\section{Materials and Methods Methods}

Preparation of BP-NCDs/MC nanocomplexes and agarose gel electrophoresis. BP-NCDs solution was prepared with ultra-pure water. After lyophilized, the solution was weighed and standardized BP-NCDs $(1 \mathrm{mg} / \mathrm{mL})$. The solution was then sterilized with a $0.22 \mu \mathrm{m}$ filter screen before use. Four miRNA mimics: miRNA-1, miRNA-133, miRNA-208, and miRNA-499 were used to prepare BPNCDs/MC nanocomplexes. Predetermined concentrations of sterilized BP-NCDs were sonicated for $15 \mathrm{~min}$, then added into the defined miRNAs-combo solution at different weight ratios used vortex for assembly. The obtained $\mathrm{BP}-\mathrm{NCD} / \mathrm{MC}$ nanocomplexes were static at room 


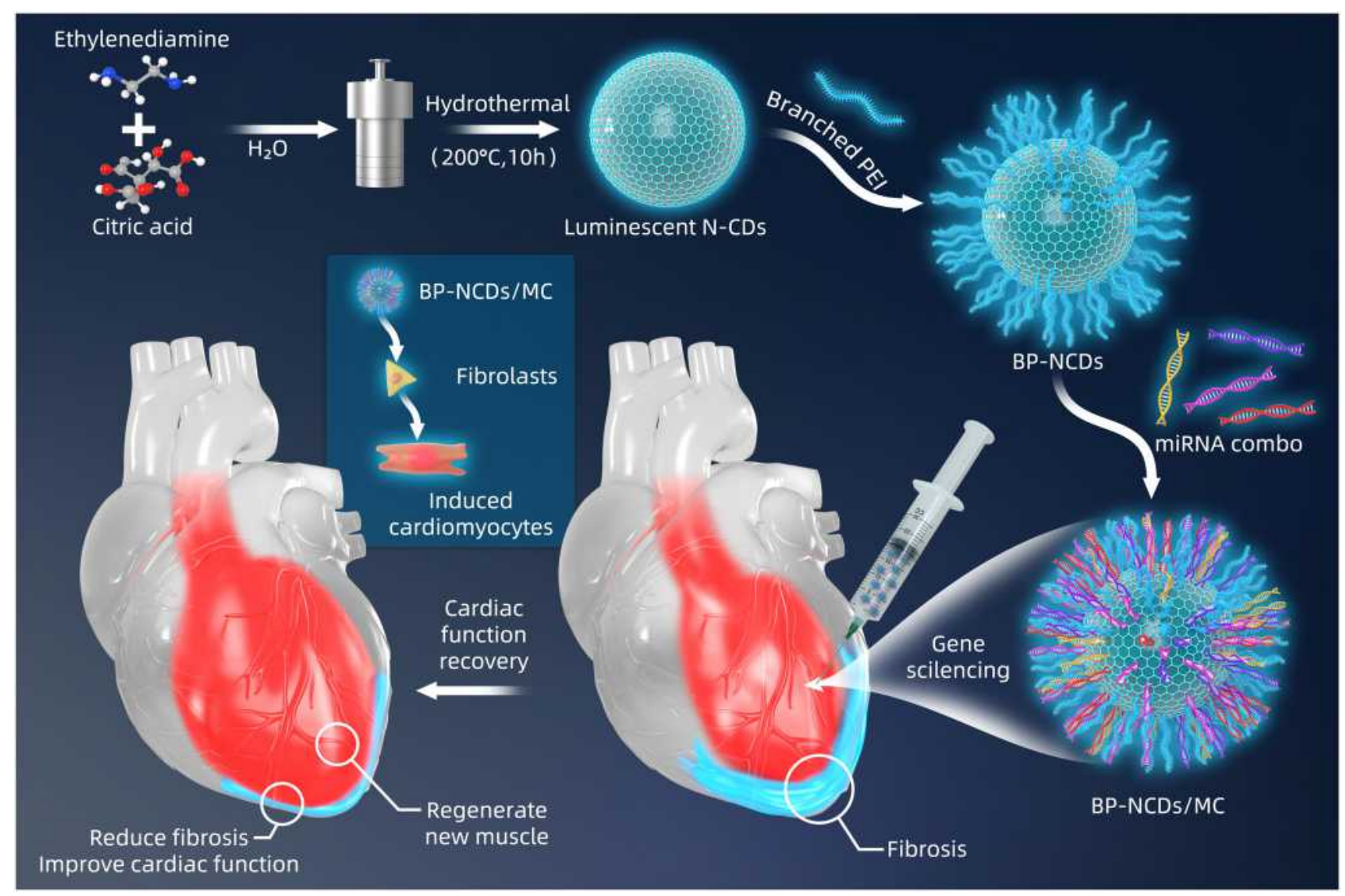

Figure I Schematic overview of experimental procedures. Surface engineering of BP-NCDs, and illustration of the BP-NCDs nanovector directly reprogram cardiac fibroblasts into cardiomyocytes following miR-combo delivery.

temperature for $15 \mathrm{~min}$ and then stored at $4^{\circ} \mathrm{C}$ for subsequent use. Next, BP-NCDs/MC nanocomplexes (miRNA1: miRNA-133: miRNA-208: miRNA-499 = 1:1:1:1:1) was selected for agarose gel electrophoresis. The nanocomplexes $(10 \mu \mathrm{L})$ solution was added to $2 \mu \mathrm{L}$ of loading buffer $(0.1 \%$ sodium dodecyl sulfate, $5 \%$ glycerol, and $0.005 \%$ bromophenol blue) and applied to a $2 \%$ agarose gel in a TAE acid buffer solution ( $\mathrm{pH}$ 8.0) containing $0.1 \mathrm{mg} / \mathrm{mL}$ ethidium bromide (EtBr). The complex was subjected to electrophoresis in TAE solution at a voltage of $120 \mathrm{~V}$ for $30 \mathrm{~min}$. The gel is imaged with a UV diopter.

\section{Cell Culture}

Cardiac fibroblasts (CFs) were extracted from the C57BL/ 6 mice on 3 days of birth. Hearts were removed from the chest of mice and rinsed with fresh PBS. Tissues were decomposed with ophthalmic scissors, and then incubated in $0.08 \%$ trypsin $(4.5 \mathrm{~mL})$ and $0.08 \%$ collagenase II (10 mg collagenase II dissolved in the $10 \mathrm{~mL}$ pure medium) for 45 minutes. After 3-4 times digestion, the cells were collected by differential centrifugation and placed in a T75 culture flask containing high glucose DMEM (10\% FBS and $1 \%$ penicillin/streptomycin). The cells passed to the third generation were transfected into BP-NCDs, BP$\mathrm{NCDs} / \mathrm{MC}$, and PEI/MC complexes in a 6-well culture plate. The transfected cells were cultured in an induction medium (10\% FBS and $1 \%$ penicillin/streptomycin). Replace the medium with the transforming growth factor- $\beta$ inhibitor SB431542 and the WNT inhibitor XAV939 after $24 \mathrm{~h}$ and replace the medium every $48 \mathrm{~h} .{ }^{16}$

\section{Cell Viability Assays}

Cardiac fibroblasts $\left(1.0 \times 10^{4}\right)$ were cultured in 96-well plates with high glucose DMEM (10\% FBS and 1\% penicillin/streptomycin) for $12 \mathrm{~h}$. Fresh serum-free medium (Opti-MEM) was added and incubated with BP-NCDs, $\mathrm{PEI} / \mathrm{MC}$, and BP-NCDs/MC for $6 \mathrm{~h}$. A quantity of $10 \mu \mathrm{L}$ CCK-8 solution was added to each well and incubated at room temperature for another $4 \mathrm{~h}$. The optical density (OD) of the mixture was measured at $450 \mathrm{~nm}$ with a microplate reader. Cardiac fibroblasts $\left(20.0 \times 10^{4}\right)$ were placed in 6-well culture plates and transfected with BP-NCDs, PEI/ 
$\mathrm{MC}$, and BP-NCDs/MC nanocomplexes for $6 \mathrm{~h}$. To remove the supernatant, wash the cells, make sure to remove the active esterase in the culture medium, add a sufficient amount of the Live \& Dead Viability Assay Kit working liquid, incubate at room temperature for 30-45 minutes, absorb the dyeing working fluid to stop incubation, wash the PBS, observe the labeled cells under the fluorescence microscope.

\section{Cellular Uptake Efficiencies}

The transfection efficiency was measured by fluorescence confocal microscopy and flow cytometry. Cardiac fibroblasts were transfected into Opti-MEM medium using BPNCDs, PEI/MC, and BP-NCDs/MC. The blank group was used as the control group. Cardiac fibroblasts were seeded in a polylysine-coated confocal dish and cultured at $37^{\circ} \mathrm{C}$ for $12 \mathrm{~h}$. When the cells adhered to the surface of the culture, the cardiac fibroblasts were transfected with Cy5labeled miRNA compound in Opti-MEM medium. After incubation at $37^{\circ} \mathrm{C}$ for $6 \mathrm{~h}$, the cells were washed with PBS, then observed using a fluorescence confocal microscopy. Flow cytometry was used to monitor the quantitative cellular uptake of nanoparticles in cardiac fibroblasts. Cardiac fibroblasts were transfected with Cy5-labeled miRNA nanocomplexes for $6 \mathrm{~h}$, then washed with PBS, followed by trypsinization, centrifugation, resuspended in $200 \mu \mathrm{L}$ of PBS containing $2 \%$ fetal bovine serum, added with $200 \mu \mathrm{L}$ of $4 \%$ paraformaldehyde, and incubated at $4^{\circ}$ $\mathrm{C}$ for $2 \mathrm{~h}$. The fluorescence intensity distribution of 10,000 cell samples was measured and analyzed using FlowJo software.

\section{Bright Field Imaging}

After transfection, the cardiac fibroblasts were cultured for 3 weeks and observed under a bright field microscope. After washing with PBS twice, the cells were observed under a Leica fluorescence microscope, and iCM cells were counted.

\section{Real-Time Quantitative Reverse Transcription Polymerase Chain Reaction}

Total RNA was extracted from cardiac fibroblasts via BPNCDs, PEI/MC, or BP-NCDs/MC complexes using standard methods and PCR using primers. The RNA was collected and purified using the EZ-Press RNA Purification Kit (EZBioscience, Fairview Ave, USA) according to the manufacturer's instructions. The total
RNA concentration was quantified using a NanoDrop spectrophotometer. RNA was reverse-transcribed into cDNA using PrimeScrip RT-PCR Kit (TaKaRa, Shiga, Japan). The quantitative real-time PCR reaction was performed using a LightCycler from Roche Molecular Biochemicals, using SYBR premixed Ex Taq (TaKaRa, Shiga, Japan), according to the protocol provided by the manufacturer. The PCR reaction process was as follows: denaturation at $95^{\circ} \mathrm{C}$ for $10 \mathrm{~min}$ (initial denaturation) followed by 30 cycles, denaturation at $95^{\circ} \mathrm{C}$ for $30 \mathrm{~s}$, then annealing at $57^{\circ} \mathrm{C}$ for $30 \mathrm{~s}$, and elongation at $72^{\circ} \mathrm{C}$ for $30 \mathrm{~s}$. GAPDH is used as an internal standard. A no template blank and a reverse transcriptional negative blank served as a negative control. $2 \wedge(-\Delta \Delta \mathrm{Ct})$ method was used to process the data. Gene expression of each factor was normalized by GAPDH. All the measurements were made in triplicates. The sequence of target primers is shown in (Table S1).

\section{Western Blotting}

After 1 and 2 weeks of transfection, the cells were washed by PBS and digested by trypsin. The cells obtained were lysed through centrifugation in an ice bath with RIPA lysis buffer containing protease inhibitor for $15 \mathrm{~min}$, followed by ultrasonic treatment for $5 \mathrm{~min}$, centrifuged at 12,000 $\mathrm{g}$ for $15 \mathrm{~min}$, and the supernatant collected. The protein concentration was determined using the Pierce BCA Protein Assay Kit (Thermo Fisher Scientific, Rockford, IL, USA), and then $5 \times$ SDS-PAGE non-reducing protein loading buffer was added and boiled at $95^{\circ}$ for $10 \mathrm{~min}$. Equivalent protein samples were separated by $10 \%$ sodium dodecyl sulfate-polyacrylamide gel electrophoresis (SDSPAGE) and transferred to polyvinylidene fluoride (PVDF) membrane. The membranes were blocked using 5\% BSA and incubated with primary antibodies against Gata4 (1:2000; Cambridge, UK, Abcam), Mef2c (1:1000; Cambridge, UK, Abcam), Tbx5 (1:1000; Cambridge, UK, Abcam), Hand2 (1:1000; Cambridge, UK, Abcam) and GAPDH (1:500; Cambridge, UK, Abcam). Then, the membrane was incubated with Goat anti-Rabbit IgG $(\mathrm{H}+$ L) Highly Cross-Adsorbed Secondary Antibody, Alexa Fluor 488 second incubation for $1 \mathrm{~h}$ at room temperature, using the LI-COR company's Odyssey two-color infrared fluorescence imaging system scans.

\section{Animals}

C57BL/6 mice were provided by and housed in an animal facility at Renji Hospital under specific pathogen-free 
(SPF) condition. All animal procedures were performed in accordance with NIH guidelines (Guide for the care and use of laboratory animals) and approved by Institutional Animal Care and Use Committee of Shanghai Jiao Tong University School of Medicine (License: SYXK (Shanghai) 2016-0009, Ethic code: A2020124).

\section{Induction and miRNA-Combo Delivery in Infarcted Hearts}

In this study, MI was induced by permanent ligation of the left anterior descending artery (LAD). To deliver the miRNA complex to the infarcted heart tissue, a pool of miRNA mimics was prepared, and $20 \mu \mathrm{L}$ of PEI/MC, BPNCDs/MC nanocomplexes were injected into the epicardium along the boundary between the infarcted area and the boundary area. Four weeks after MI and injection of miRNA complex, the heart was retrogradely perfused with PBS containing 4\% PFA through the right carotid artery. Paraffin-embedded tissue sections (Torrance, CA, Sakura Finetek) were then performed. Infarct size (percentage of fibrosis length and infarct thickness) was shown by Masson staining. The heart sections were observed under a light microscope (Tokyo, Japan, Olympus). The area of fibrotic tissue was then measured using ImageJ software version 1.8.0 (National Institutes of Health) and expressed as the percentage of the fibrosis area and infarct thickness.

\section{Immunofluorescence Staining}

After transfection of $\mathrm{PEI} / \mathrm{MC}$ and $\mathrm{BP} \mathrm{NCDs} / \mathrm{MC}$ nanocomplexes, the digested cell suspension was transferred to the confocal culture dish. After PBS washing, 4\% polyformaldehyde fixed $1 \mathrm{~h}$, after PBS washing, with $0.2 \%$ of Triton $\mathrm{X}-100$ rupture in $1 \mathrm{~h}$ at room temperature, with PBS washing three times, add a goat serum albumin (GSA, Shanghai, China, Beyotime), down closed 2h at room temperature, out of confining liquid washing after adding suitable amount of COL1A1 (1:200; Cambridge, UK, Abcam), cTnI (1:500; Cambridge, UK, Abcam). The antibodies in each petri dish were then placed in a wet box and incubated overnight at $4^{\circ} \mathrm{C}$. And then incubated with secondary antibodies (Goat Anti-Mouse IgG H\&L (Alexa Fluor 488); Goat Anti-Mouse IgG H\&L (Alexa Fluor 647), Cambridge, UK, Abcam) and 4',6-diamidino-2- phenylindole (DAPI) for $1 \mathrm{~h}$ at room temperature. After washed with TBST (Shanghai, China, Beyotime), the cells were visualized under a Nikon fluorescence microscope.

For immunohistochemistry, heart tissues were stained with CD31 (1:200; Cambridge, UK, Abcam) for $24 \mathrm{~h}$ at $4^{\circ}$ $\mathrm{C}$ and then incubated with secondary antibodies (Goat Anti-Mouse IgG H\&L (Alexa Fluor 647), Cambridge, UK, Abcam) and DAPI for $1 \mathrm{~h}$ at room temperature. Sections were observed under a universal Nikon fluorescence microscope.

\section{Statistical Analysis}

All data were expressed as mean \pm SEM of three independent experiments. The $\mathrm{n}$ value represents the number of independent experiments conducted, the number of individual experiments, or the number of mice. $\mathrm{P}<0.05$ was considered significant $(* \mathrm{p}<0.05, * * \mathrm{p}<0.01$, ***p $<$ $0.001, * * * * \mathrm{p}<0.0001)$. One-way analysis of variance (ANOVA) was used for the analysis of significant differences between groups. After confirming the normal distribution, Tukey multiple-comparison test and Student's $t$-test were used for the double-component comparison. Prism GraphPad Software was used for statistical analysis.

\section{Results and Discussion Synthesis and Characterization of BP-NCDs/MC Nanocomplexes}

The synthesis of BP-NCDs/MC nanocomplexes involved three steps: (i) synthesis of N-doped CDs (N-CDs), (ii) grafting branched PEI on the surface of carboxyl-capped $\mathrm{N}-\mathrm{CDs}$ (BP-NCDs), and (iii) construction of BP-NCDs /MC nanocomplex through the electrostatic interactions between positive-charged BP-NCDs and negativecharged miRNAs-combo (miRNA-1, miRNA-133, miRNA-208, and miRNA-499) (Figure 1). Transmission electron microscope (TEM) and Atomic force microscopy (AFM) images give the morphological information of $\mathrm{N}-\mathrm{CDs}$, and BP-NCDs. N-CDs exhibited a mean diameter of $30.5 \mathrm{~nm}$ by TEM analysis (Figure 2A). The size of BPNCDs was mainly about $41.0 \mathrm{~nm}$, showing a $10.5 \mathrm{~nm}$ increase compared to the bare N-CDs (Figure 2B). Meanwhile, the functionalization of BP-NCDs led to a height increase from $0.42 \mathrm{~nm}$ to $0.90 \mathrm{~nm}$ by the AFM analysis (Figure $2 \mathrm{C}$ and $\mathrm{D}$ ). The average hydrodynamic size of the BP-NCDs measured by DLS was $42.1 \mathrm{~nm}$, which was slightly larger than that of the bare N-CDs $(30.4 \mathrm{~nm})$ due to the presence of the polymer PEI envelope (Figure 2E). ${ }^{47}$ The surface charge of BP-NCDs reflects 

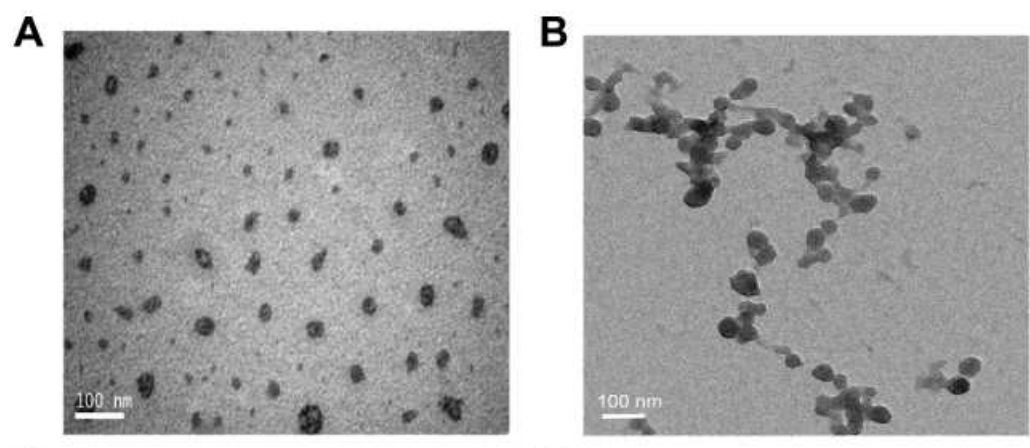

C

D
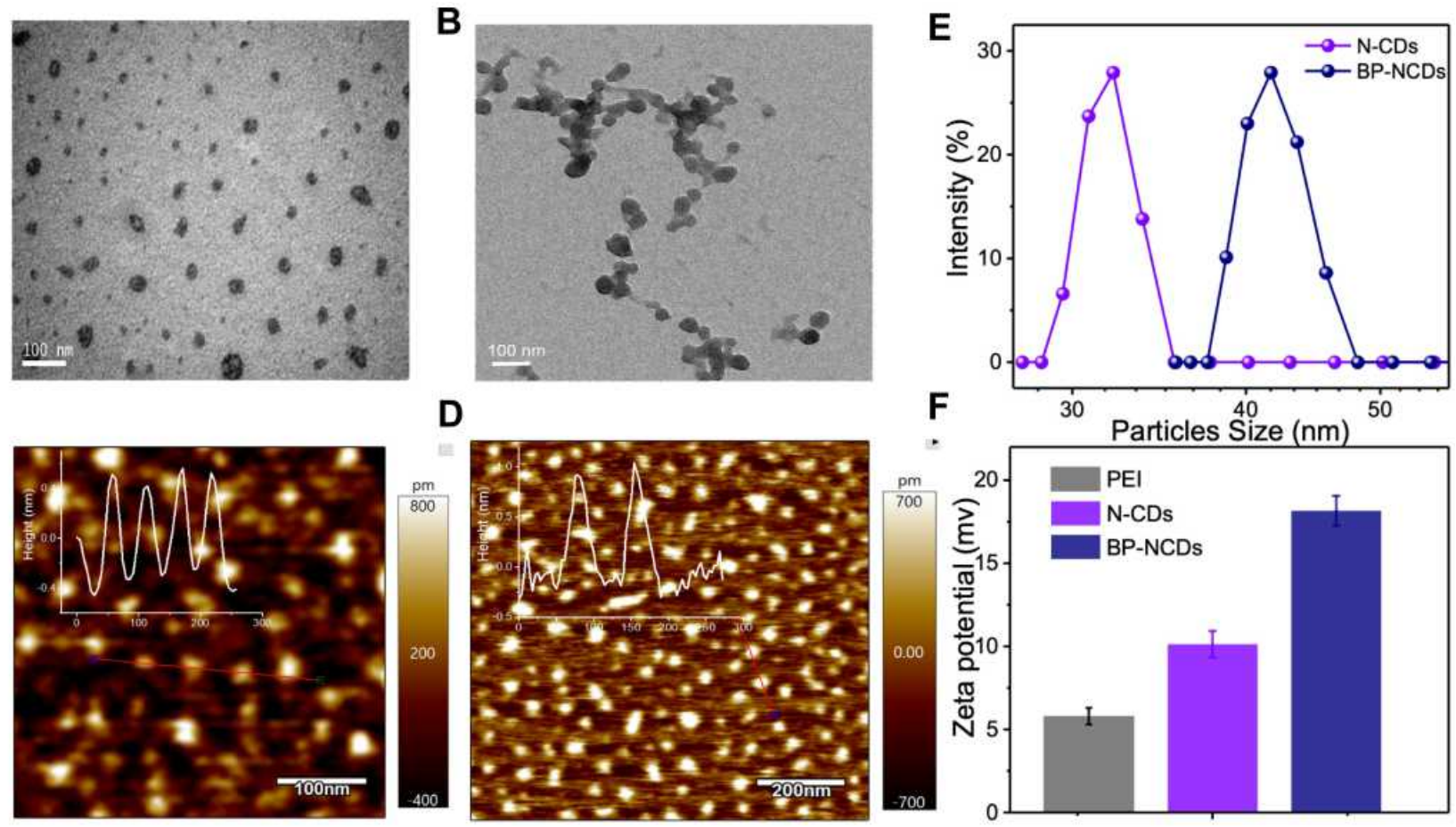

Figure 2 (A) TEM characterization image of bare N-CDs. (B) TEM characterization images of BP-NCDs. (C) AFM images of bare N-CDs. (D) AFM images of BP-NCDs. (E) Dynamic light scattering (DLS) for bare N-CDs and BP-NCDs. (F) Zeta potential of PEl, bare N-CDs, and BP-NCDs. [N-CDs] = 50.0 $\mu \mathrm{g} \mathrm{mL}-\mathrm{I}$, [BP-NCDs] = $50.0 \mu \mathrm{g} \mathrm{mL}-\mathrm{I}$, $\mathrm{PH}=7.4$.

the capability of cationic-related carriers for nucleic acid delivery. ${ }^{43}$ Zeta potential analysis demonstrated that the surface charge of N-CDs, branch PEI, and BP-NCDs was $7 \mathrm{mV}, 10 \mathrm{mV}$, and $18 \mathrm{mV}$, respectively (Figure $2 \mathrm{~F}$ ). These results together suggest that branched PEI was successfully grafted on the surface of the N-CDs. ${ }^{4-47}$

The X-ray-photoelectron spectroscopy (XPS) measurements were carried out to elucidate the difference in the elemental composition of pure N-CDs and BP-NCDs. The full scan of XPS spectra showed three prominent peaks at $284 \mathrm{eV}, 401 \mathrm{eV}$, and $532 \mathrm{eV}$ attributed to $\mathrm{C} 1 \mathrm{~s}, \mathrm{~N} 1 \mathrm{~s}$, and $\mathrm{O} 1 \mathrm{~s}$, respectively. The relative elemental analysis showed an increase of carbon and nitrogen levels in BP-NCDs, with an associated decrease in oxygen content (67.34 at \% $\mathrm{C} 1 \mathrm{~s}, 17.10$ at $\% \mathrm{~N} 1 \mathrm{~s}$ and 15.56 at \% O1s) when compared to the $\mathrm{N}-\mathrm{CDs}(53.02$ at $\% \mathrm{C} 1 \mathrm{~s}, 8.53$ at $\% \mathrm{~N} 1 \mathrm{~s}$ and 38.45 at. $\% \mathrm{O} 1 \mathrm{~s}$ ) (Figure $3 \mathrm{~A}$ ). In the high-resolution $\mathrm{C} 1 \mathrm{~s}$ spectrum of N-CDs, three peaks attribute to $\mathrm{C}-\mathrm{C}$ or $\mathrm{C}=\mathrm{C}\left(\mathrm{sp}^{2}, 284.4\right.$ $\mathrm{eV}), \mathrm{C}-\mathrm{N}$, or $\mathrm{C}-\mathrm{O}\left(\mathrm{sp}^{3}, 285.2 \mathrm{eV}\right), \mathrm{C}=\mathrm{O}\left(\mathrm{sp}^{3}, 287.5 \mathrm{eV}\right)$ bonds were observed. However, the high-resolution $\mathrm{C} 1 \mathrm{~s}$ spectrum of BP-NCDs showed four peaks, presumably due to the formation of amide groups between the carboxylic group of N-CDs and the amine group of branched PEI (Figure 3B). The two main peaks of the N1s spectrum for
BP-NCDs were associated with the pyridinic N $(399.5 \mathrm{eV})$ and the quaternary $\mathrm{N}(401.5 \mathrm{eV})$. Simultaneously, the two main peaks of the N1s spectrum for N-CDs was linked to the pyrrolic $\mathrm{N}(399.9 \mathrm{eV})$ and quaternary $\mathrm{N}(401.8 \mathrm{eV})$ (Figure 3C). This change is likely due to the formation of the amide bonds, which is in good agreement with the $\mathrm{C} 1 \mathrm{~s}$ XPS spectrum. ${ }^{46}$ The functional groups and chemical compositions of N-CDs and BP-NCDs were further identified by Fourier transform infrared (FT-IR) spectra (Figure 3D). N-CDs revealed a broad peak at $3408 \mathrm{~cm}^{-1}$, which confirms the existence of hydroxyl(-OH) groups from the carboxylic groups and water molecules or $\mathrm{N}-\mathrm{H}$ stretching from the amine structure. The sharp peak at $1698 \mathrm{~cm}^{-1}$ is typical for carbonyl $(\mathrm{C}=\mathrm{O})$ groups. Specifically, the band at $1400 \mathrm{~cm}^{-1}$ showed the stretching and bending vibrations of the $\mathrm{C}-\mathrm{C}$ bond, and the peak at $1122 \mathrm{~cm}^{-1}$ was ascribed to $\mathrm{C}-\mathrm{O}$ stretching, which is often found in the oxidized carbons. While a broad peak loaded at $3338 \mathrm{~cm}^{-1}$ was attributed to the -OH group and carboxyl group of BPNCDs. The apparent absorption amide I $\left(1636 \mathrm{~cm}^{-1}\right)$ and amide bands II $\left(1573 \mathrm{~cm}^{-1}\right)$ peaks corresponded to the amide of -CONH- groups in the PEI functionalized N-CDs. The crystallinity of the bare N-CDs was examined by X-ray diffraction (XRD). The XRD pattern exhibited 

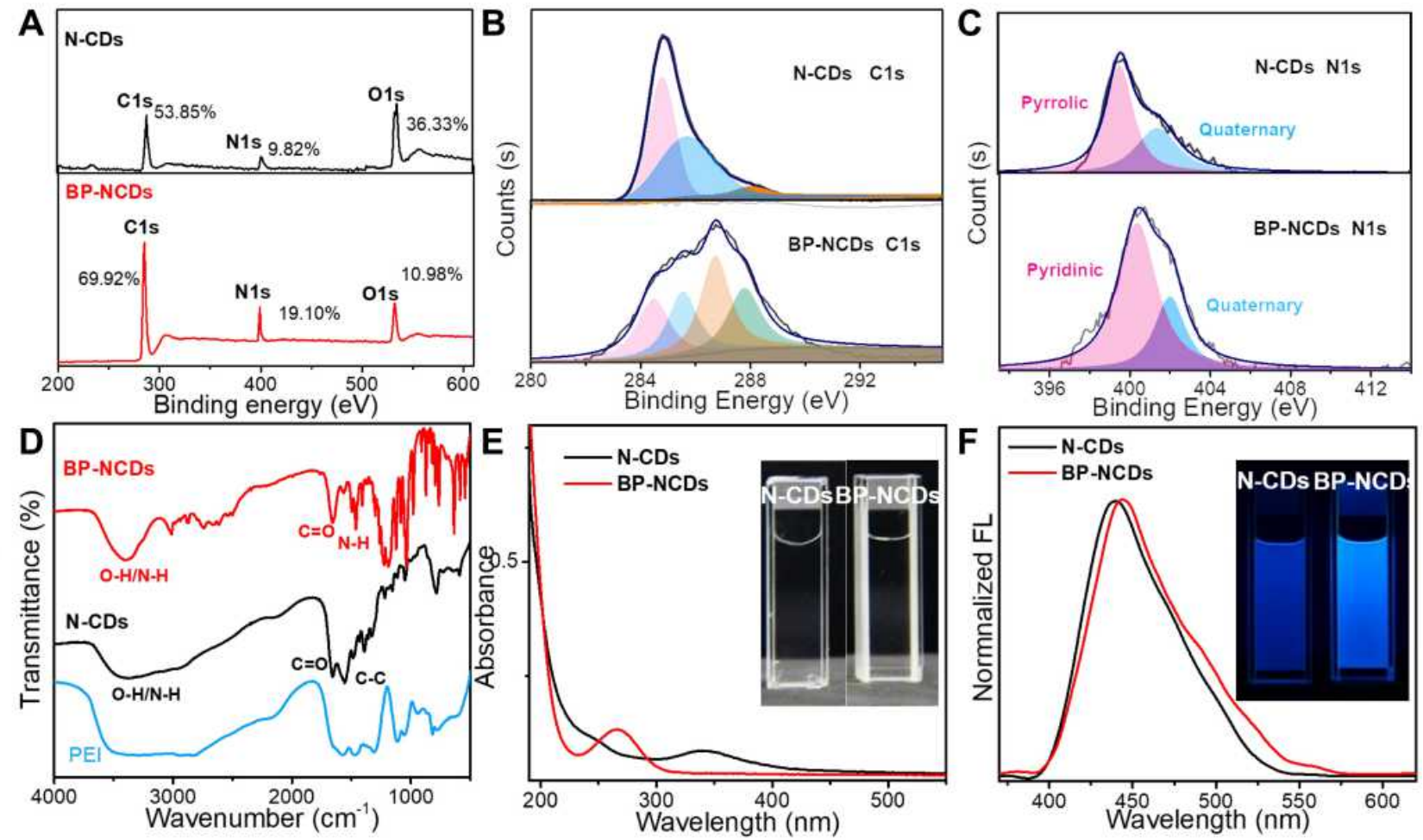

Figure 3 Compositional characterization of N-CDs and BP-NCDs. (A) The full scan of XPS spectra of N-CDs and BP-NCDs. (B) High-resolution XPS Cls spectra of $\mathrm{N}-\mathrm{CD}$ s and BP-NCDs. (C) High-resolution XPS NIs spectra of N-CDs and BP-NCDs. (D) FT-IR spectra of N-CDs, BP-NCDs, and PEI. (E) UV-vis spectra of N-CDs and BPNCDs, the inset are photographs of N-CDs and BP-NCDs solutions under a visible light, respectively. (F) FL spectra of N-CDs and BP-NCDs, the inset are photographs of $\mathrm{N}-\mathrm{CD}$ s and BP-NCDs solutions under UV light (365 nm), respectively.

a broad peak between $20^{\circ}$ and $35^{\circ} 2 \theta$, which is attributed to the graphitic structure of carbon ${ }^{47}$ (Figure S1).

In the UV-vis experiment, the maximum absorption peak of N-CDs was located at $345 \mathrm{~nm}$. After the N-CDs were functionalized with branched PEI, the band of BPNCDs blue-shifted to $270 \mathrm{~nm}$. The inset in Figure $3 \mathrm{E}$ are photographs of bare N-CDs and BP-NCDs solutions under a visible light. An excitation-dependent fluorescence spectrum of N-CDs was observed firstly, and 350 $\mathrm{nm}$ is the optimal excitation wavelength (Figure S2). The bare N-CDs showed a strong fluorescence spectrum peak at $440 \mathrm{~nm}$ when excited at $350 \mathrm{~nm}$. The maximum emission peak of BP-NCDs red-shifted to $445 \mathrm{~nm}$, and the inset in Figure 3F are photographs of bare N-CDs and BP-NCDs solutions under UV light (365 nm). These results suggested that the surface passivation by PEI imparted a strong influence on the optical properties of $\mathrm{N}-\mathrm{CDs}$ due to a change in the chemical functional groups. ${ }^{47}$ Furthermore, the time-resolved fluorescence spectrum measured with an excitation at $350 \mathrm{~nm}$ showed that the fluorescence lifetime of N-CDs is $3.35 \mathrm{~ns}$ (Figure S3).

\section{Agarose Gel-Retardation Study}

Agarose gel delay studies were conducted under different BP-NCDs/miRNA weight ratios to test the potential of BPNCDs as efficient gene delivery vectors. The mass ratio of BP-NCDs/miRNAs was set as 1:1, 2:1, 3:1, 4:1, and 5:1. The corresponding results showed that when the mass ratio of BP-NCDs/miRNAs was increased to $4: 1$, miRNAs remained completely in the original pore without simulating the migration of miRNAs in the gel (Figure 4A). This finding indicated that BP-NCDs has an excellent complexing ability with miRNAs-combo due to its good positive surface charge.

\section{Cell Viability Assay}

The cytotoxicity of BP-NCDs and BP-NCDs/MC nanocomplexes with the same miRNAs-combo weight was examined by CCK-8 method. The PEI/MC group was used as a positive control. The measured absorbance is normalized to the absorbance of the untreated cells. The results showed that the viability of cardiac fibroblasts culture in BP-NCDs and BP-NCDs/MC nanocomplexes was higher than that in $\mathrm{PEI} / \mathrm{MC}$ group (BP-NCDs 


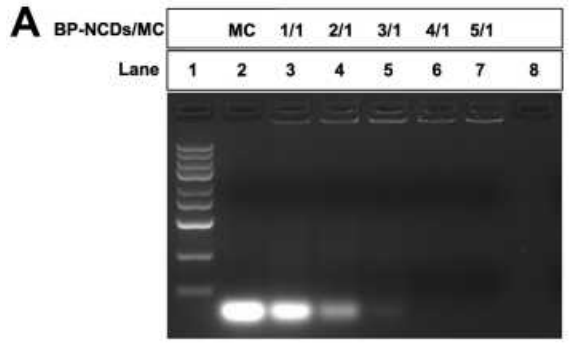

C

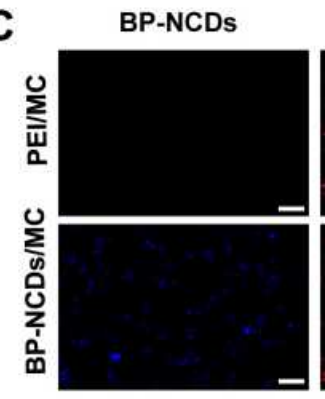

Cy5
B
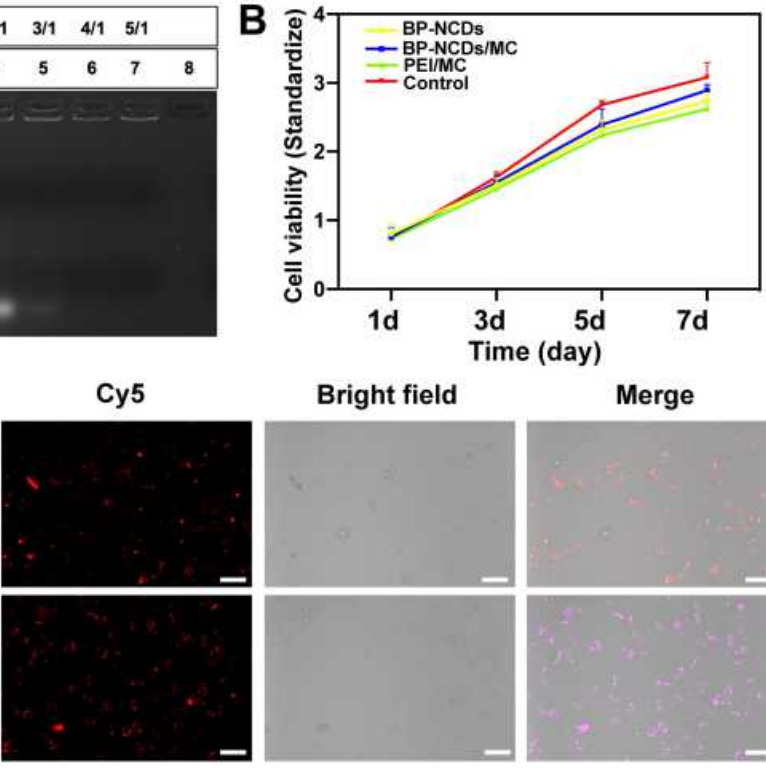

Bright field

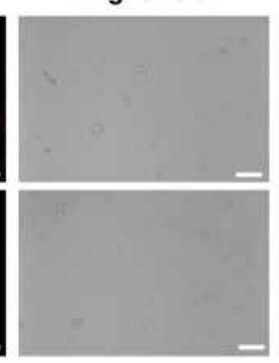

Merge

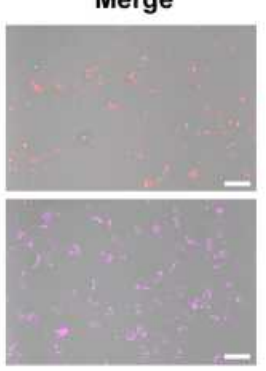

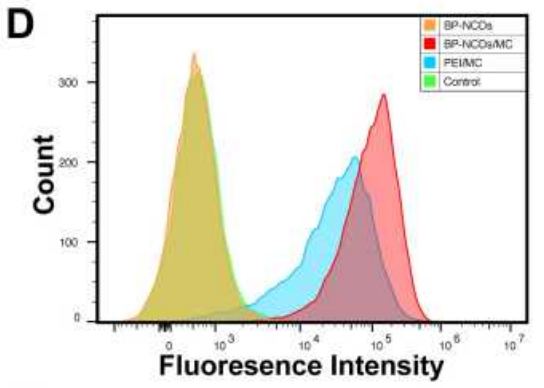

E

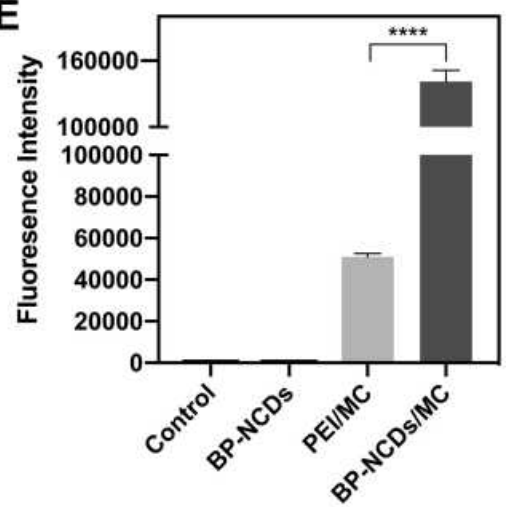

Figure 4 (A) Agarose gel electrophoresis retardation assay for various miRNA nanocomplexes. (B) Cell viability and proliferation after culture for I to 7 days. (C) Fluorescent confocal microscopy images of CFs following incubation with various samples loaded with miRNA combo for $24 \mathrm{~h}$ (scale bar: $75 \mu \mathrm{m}$ ). Intracellular transfection and delivery efficiencies of miRNAs-combo using various nanocomplexes. Negative miRNA was Cy5 labeled (red). (D) Flow cytometry profiles of CFs after a 24 $\mathrm{h}$ transfection with Cy5-labeled negative miRNAs delivered by PEI/MC and BP-NCDs/MC nanocomplexes (2.5 $\mu \mathrm{g}$ miRNAs in $10 \mu \mathrm{L}$ BP-NCDs). The transfection efficiency of miRNAs was analyzed by quantifying miRNAs expression and cell-uptake ability. (E) Relative fluorescence intensity of CFs after a $24 \mathrm{~h}$ incubation with various nanocomplexes based on flow cytometry results. The data represent mean \pm SEM; one-way ANOVA, $*_{p}<0.05, * * p<0.01$, ***p $<0.001$, $* * * * p<0.000$ I.

/miRNAs mass ratio of 4:1) (Figure 4B). Twenty-four hours after transfection of the same mass of miRNAs in the growth medium, the Live/Dead assay (Calcein AM) indicated excellent cell viability associated with the BPNCDs/MC group compared to the BP-NCDs and PEI/MC groups (Figure $\mathrm{S} 4$ ). This result suggested that small-sized BP-NCDs have good biocompatibility in gene delivery.

\section{Transfection and Delivery of miRNAs-Combo by BP-NCDs}

We evaluated the ability of BP-NCDs as gene vectors using functionalized fluorescent carbon dots constructs. Blue fluorescence was observed from the intracellular BPNCDs (Figure 4C, blue field). After miRNAs-combo hybridized with intracellular target mRNA, the fluorescent dye was isolated from the quencher and dissociated from the duplex structure on the surface of BP-NCDs to produce red fluorescence (Figure $4 \mathrm{C}$, red field). The quantification of the extent of nanoparticle internalization by blue and red fields coverage and fluorescence-activated cell sorting (FACS) further confirmed that BP-NCDs cell uptake is higher than PEI (Figure 4D and E). These results indicated that miRNAs-combo were effectively transferred into cells, which led to the up-regulation of intracellular miRNAs levels. The multifunctional BP-NCDs designed in this work are efficient in cell gene regulation and fluorescence imaging.

\section{BP-NCDs Nanocomplexes Directly Induced Cardiac Fibroblasts to be Reprogrammed Into Functional iCMs in vitro}

We examined the presence of cell colony morphology in BP-NCDs, PEI/MC, and BP-NCDs/MC groups using iCMs. BP-NCDs/MC group had a significant amount of iCMs within 3 weeks, and we observed that the transduction of BP-NCDs/MC to iCMs produced higher contractile activity as well as more iCMs than the BP-NCDs group (Figure 5A). The expression of iCMs gene in cells transfected with BP-NCDs/MC nanocomplex was measured to demonstrate the effect of miRNA transfection on the direct reprogramming of myocardial fibroblasts at the mRNA level (Figure 5C). In carrying out this experiment, specific genes during myocardial development as well as maturation, ie, GATA Binding Protein 4 (GATA4), Myocyte enhancer factor 2C (MEF2C), Natriuretic Peptide A (NPPA), Myosin Heavy Chain 7 

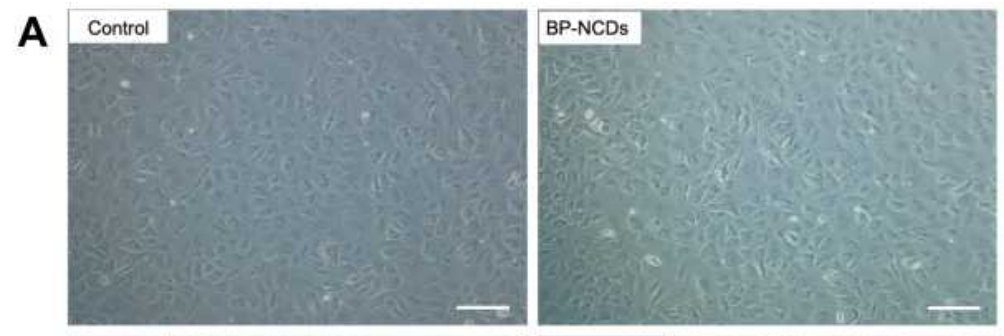

B

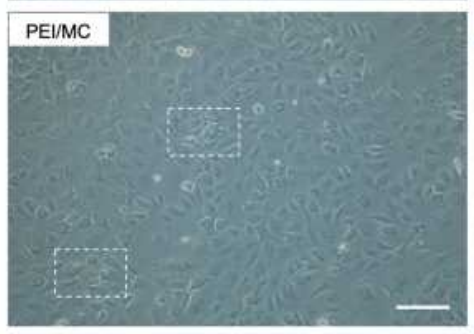

BP-NCDs/MC
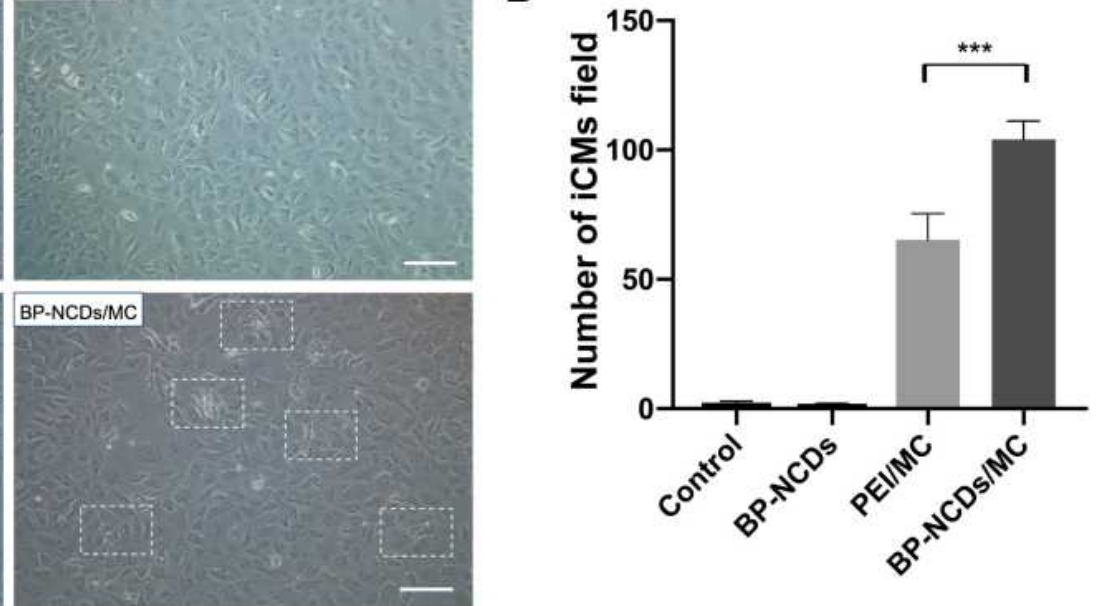

C

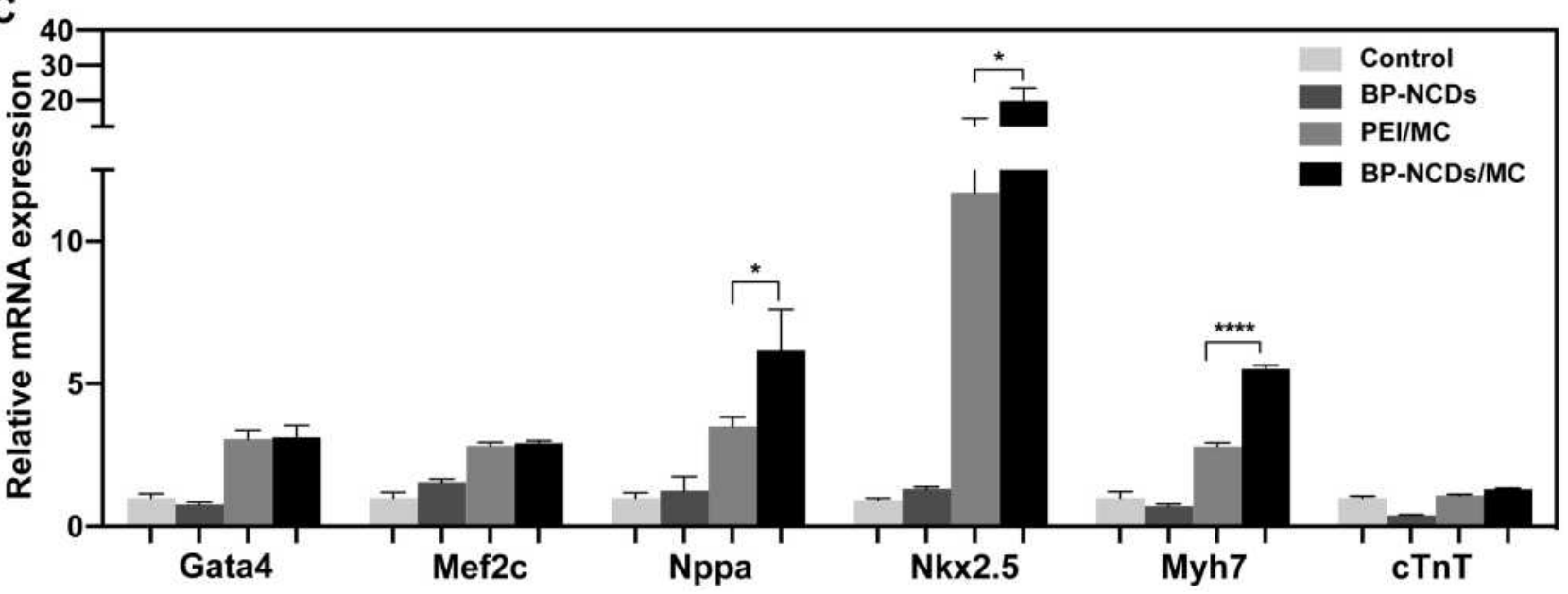

Figure 5 (A) Bright field images of iCMs in control, BP-NCDs, PEI/MC, and BP-NCDs/MC (2.5 $\mu$ g miRNAs in $10 \mu \mathrm{L}$ BP-NCDs) transduced cardiac fibroblasts. Scale bar = $50 \mu \mathrm{m}$. (B) Quantification of iCMs cells in control, BP-NCDs, PEI/MC, and BP-NCDs/MC transduced cardiac fibroblasts. (C) qRT-PCR analysis of cardiomyocyte associatedgenes, Gata4, NPPA, Nkx2-5, Mef2c, Myh7, cTnT2. Scale bar $=50 \mu \mathrm{m}$. The data represent mean \pm SEM; one-way ANOVA, *p $<0.05$, **p $<0.01$, ***p $<0.001$, ****p $<$ 0.0001 .

(MYH7), NK2 Homeobox 5 (NKX2-5), Troponin T2, Cardiac Type (TNNT2) were selected. On day 7, the iCMs gene expression in the BP-NCDs group was not significantly different from that of the control group. The cells transfected with $\mathrm{PEI} / \mathrm{MC}$ and the cells transfected with BP-NCDs/MC nanocomplex were elevated considerably in myocardial-specific gene expression relative to the control cells. Regarding the expression of the genes (ie, GATA4, MEF2C, NPPA, NKX2-5) in the early stage of cardiac development, the cells transfected with PEI/ MC nanocomplex were almost no different from those transfected with BP-NCDs/MC. In contrast, the cells transfected with BP-NCDs/MC nanocomplex were higher than those transfected with $\mathrm{PEI} / \mathrm{MC}$ in the expression of genes (MYH7, TNNT2) in the late maturation of the heart.
Transcription factors in early cardiac development are crucial to the successful reprogramming of fibroblasts to iCMs, ${ }^{8}$ and the high expression of cardiac transcription factors Gata4, Hand2, Mef2c, and Tbx5 proteins has been shown to transform fibroblasts into cardiac progenitors effectively. ${ }^{46}$ We used Western blotting to detect proteins that play an important role in the reprogramming process, including GATA Binding Protein 4 (Gata4), Myocyte Enhancer Factor 2C (Mef2c), T-Box Transcription Factor 5 (Tbx5), and Heart and Neural Crest Derivatives Expressed 2 (Hand2). As shown after 7 and 14 days of incubation in BP-NCDs, PEI/MC, BP-NCDs/MC, and the control groups, myocardial development-related proteins were not expressed. The expression levels of myocardial development-related proteins were significantly upregulated in the $\mathrm{PEI} / \mathrm{MC}$ and $\mathrm{BP}-\mathrm{NCD} / \mathrm{MC}$ groups. 

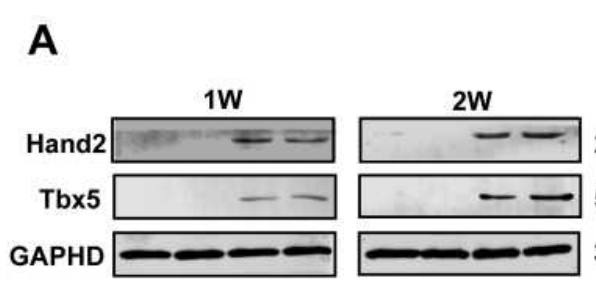

$26 \mathrm{KDa}$

$58 \mathrm{KDa}$ $37 \mathrm{KDa}$
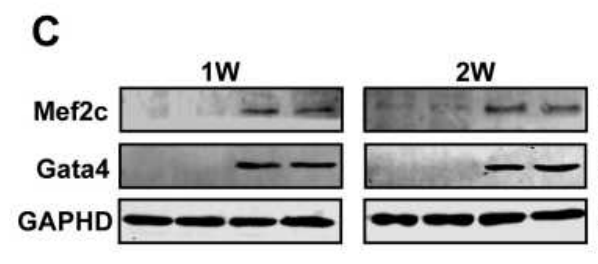

B

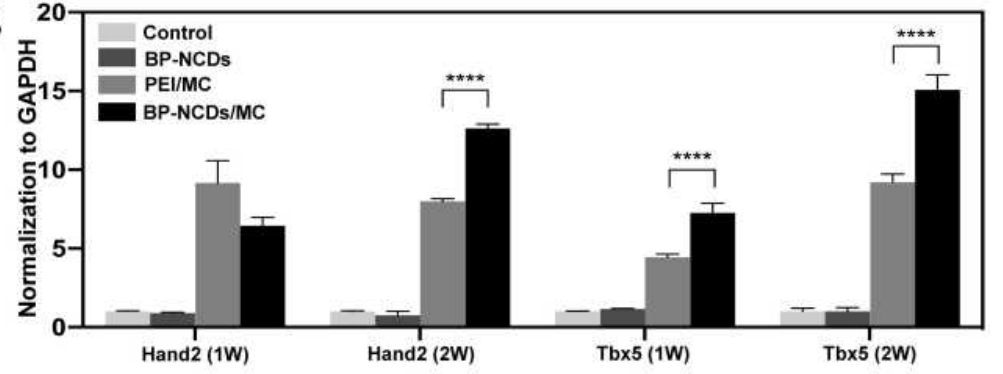

D

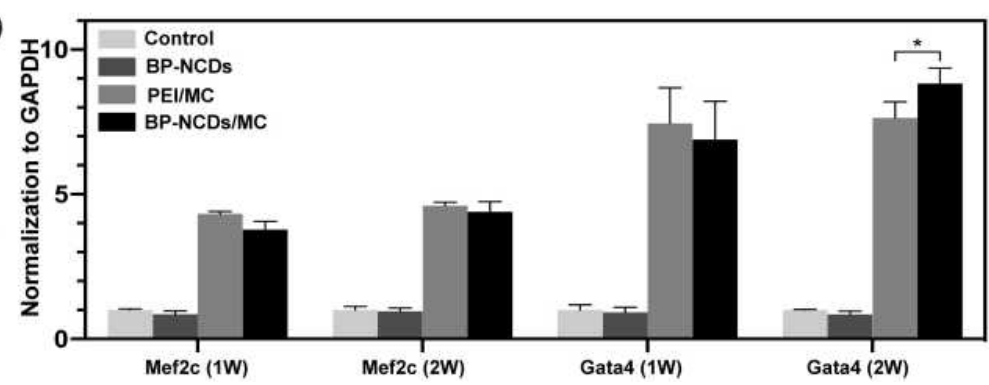

Figure 6 (A, C) Western blot analysis of cardiac early developmental transcription factors, Gata4, Hand2, Mef2c, and Tbx5. (B, D) The graph presents the quantification of Gata4, Hand2, Mef2c, and Tbx5 levels normalized to GAPDH levels. The data represent mean \pm SEM; one-way ANOVA, ${ }^{*} p<0.05, * * *_{p}<0.01, * * * p<0.001, * * * * p<0.0001$.

Moreover, the expression level of BP-NCDs/MC group was higher than that of the PEI/MC group (Figure 6A and $\mathrm{B})$. In summary, our results showed that both the $\mathrm{PEI} / \mathrm{MC}$ and BP-NCDs/MC groups significantly increased the expression of Gata4, Mef2c, Tbx5, Hand2, which was consistent with our real-time PCR results.

Cardiac fibroblasts have the potential to differentiate, but in vitro, the function of iCMs derived from cardiac fibroblasts is not mature. Since transdifferentiating is thought to be a long and random process, it would be interesting to produce a fully reprogrammed iCM. In previous studies, cardiac fibroblasts had been reprogrammed to resemble cardiac muscle cells after being maintained in the induction medium for 4 to 11 weeks. ${ }^{11-20}$ In this study, cardiac fibroblasts were transfected with PEI/MC and BP-NCDs/MC and cultured in the induction medium for 4 weeks. And through immunofluorescence staining, we observed that differentiated cells expressed iCMs marker proteins such as cTnI (Figure 7). In other reports, fibroblast genes were gradually inhibited during the reprogramming of iCMs. ${ }^{47-50}$ miRNA-133 direct target Snail $3{ }^{\prime}$ UTR and restrain fiber mother cell surface markers such as COL1A1, COL1A2, POSTN, promote fibroblasts transition to the heart muscle cells. ${ }^{21}$ With the reprogramming, the expression of COL1A1 decreases over time. Therefore, these results indicated that BP-NCDs/MC nanocomplexes significantly enhanced the expression of myocardial development and related proteins. The binding gene expression results showed that the functionalized BP-NCDs/MC nanocomplexes delivered a significant process of promoting cardiac fibroblasts to iCMs. These results suggest that cardiac reprogramming initiates iCMs reprogramming by activating endogenous GHMT genes while inhibiting fibrosis pathways. Therefore, fibrosis may be a major obstacle to cardiac reprogramming, and future research should focus on effective suppression of fibrosis. ${ }^{19-21}$

\section{BP-NCDs/MC Nanocomplexes Improves the Treatment of Myocardial Infarction in vivo}

Related studies have shown that after viral gene transfer, fibrosis is reduced in the body to improve heart function. ${ }^{14}$ Therefore, we proposed that BP-NCDs/MC nanocomplexes could effectively promote myocardial infarction (MI) damage repair. To verify this, we induced cardiac damage by coronary artery ligation and injection of BP-NCDs/MC nanocomplexes into the myocardium at the infarct junction of a mouse heart. After 4 weeks of transduction, we evaluated the efficacy of BP-NCDs/MC nanocomplex in the mice compared to the control group (ie, untreated group). Surprisingly, the infarct area and scar area of MI mice treated with BPNCDs/MC nanocomposite were significantly reduced compared to the control group (Figure 8A). Besides, in 

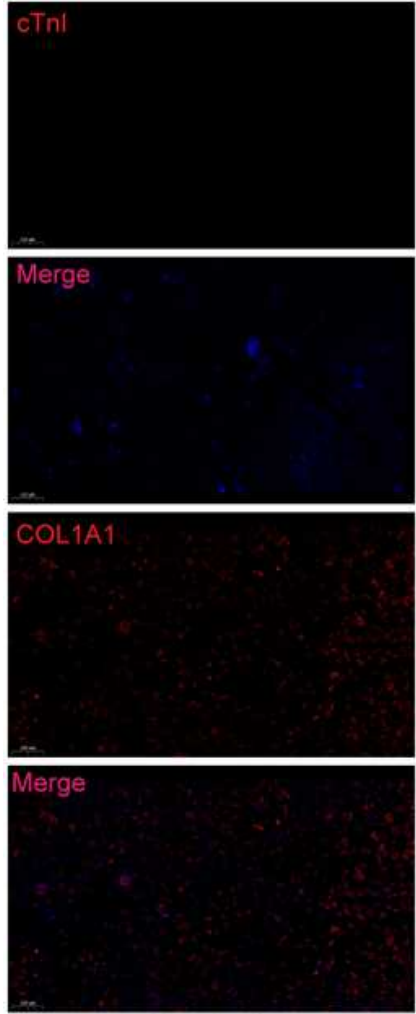

Control
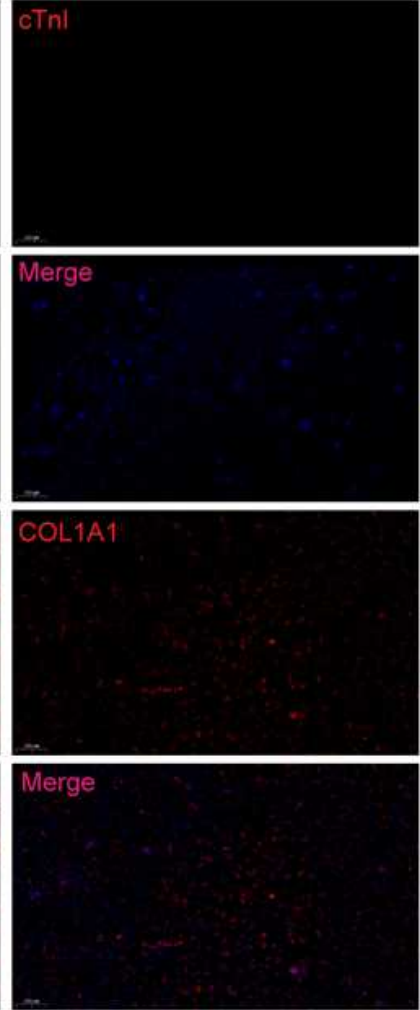

BP-NCDs
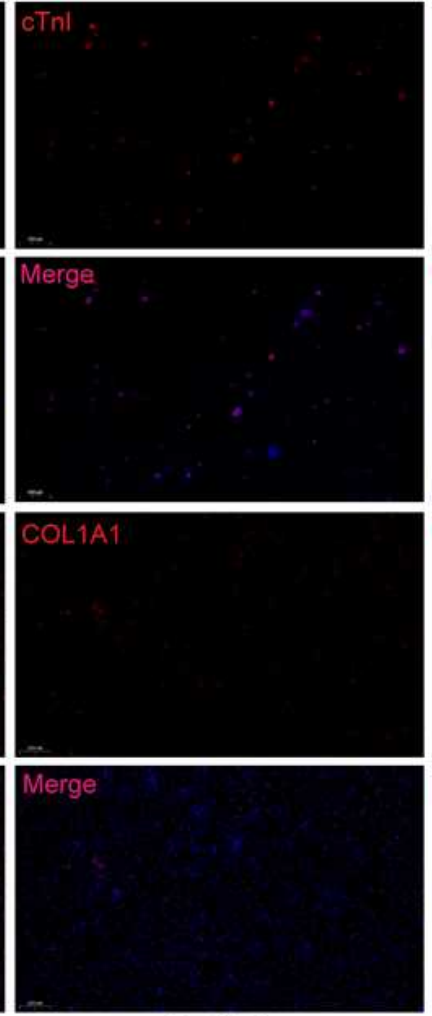

PEI/MC
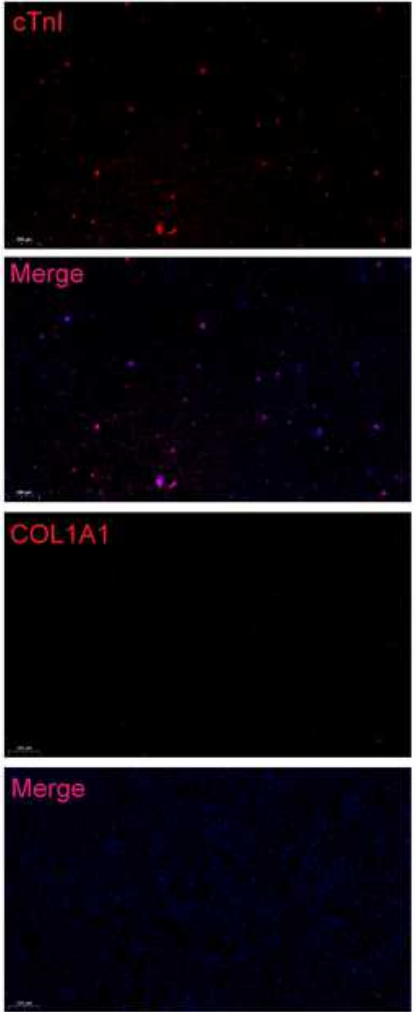

BP-NCDs/MC

Figure 7 Immunofluorescence staining for the expression of the cardiac marker cTnl and fibroblast marker COLIAI after infection with BP-NCDs, PEI/MC, and BP-NCDs IMC (2.5 $\mu \mathrm{g}$ miRNAs in $10 \mu \mathrm{L}$ BP-NCDs). COLIAI Scale bar $=200 \mu \mathrm{m}, \mathrm{cTnl}$ Scale bar $=500 \mu \mathrm{m}$.

the BP-NCDs/MC nanocomplexes treatment group, the fibrotic area and infarct thickness significantly decreased (Figure 8B and C). Immunohistochemical examination was performed 4 weeks later, with histological sections taken at the infarct site, and CD31 was used as a marker of cardiac regeneration to assess fibrosis. In the PEI/MC and BP-NCDs/MC treatment group, CD31 were significantly increased compared to the control and BP-NCDs group (Figure 8D and E).

\section{Conclusion}

In summary, the surface of N-CDs was successfully modified using branched polyethyleneimine (BP, 25 $\mathrm{kDa}$ ), resulting in $\mathrm{BP}-\mathrm{NCDs}$, which can be used as non-viral vectors for miRNAs-combo (miRNA-1, 133, 208, and 499) delivery. The BP-NCDs nanovector showed high miRNAs-combo binding affinity, stable expression in cells, excellent cellular uptake, and low levels of cytotoxicity. Additionally, BP-NCDs/MC nanocomplexes significantly enhanced the direct reprogramming of fibroblasts into $\mathrm{iCMs}$ without genomic integration, and the injection of BP-NCDs/MC nanocomplexes into mouse infarcted hearts significantly improved the quality, and quantity of cardiac functions after myocardial infarction (MI). Thus, our results suggest that BP-NCDs/MC nanocomplexes-mediated cardiac reprogramming might improve the safety and efficiency of therapeutic in heart injury. Although direct transformation induced by the non-viral vector remains a challenge and has a long way to go before clinical applications, this work may provide a strong support for further developing transdifferentiating techniques for clinical applications. 


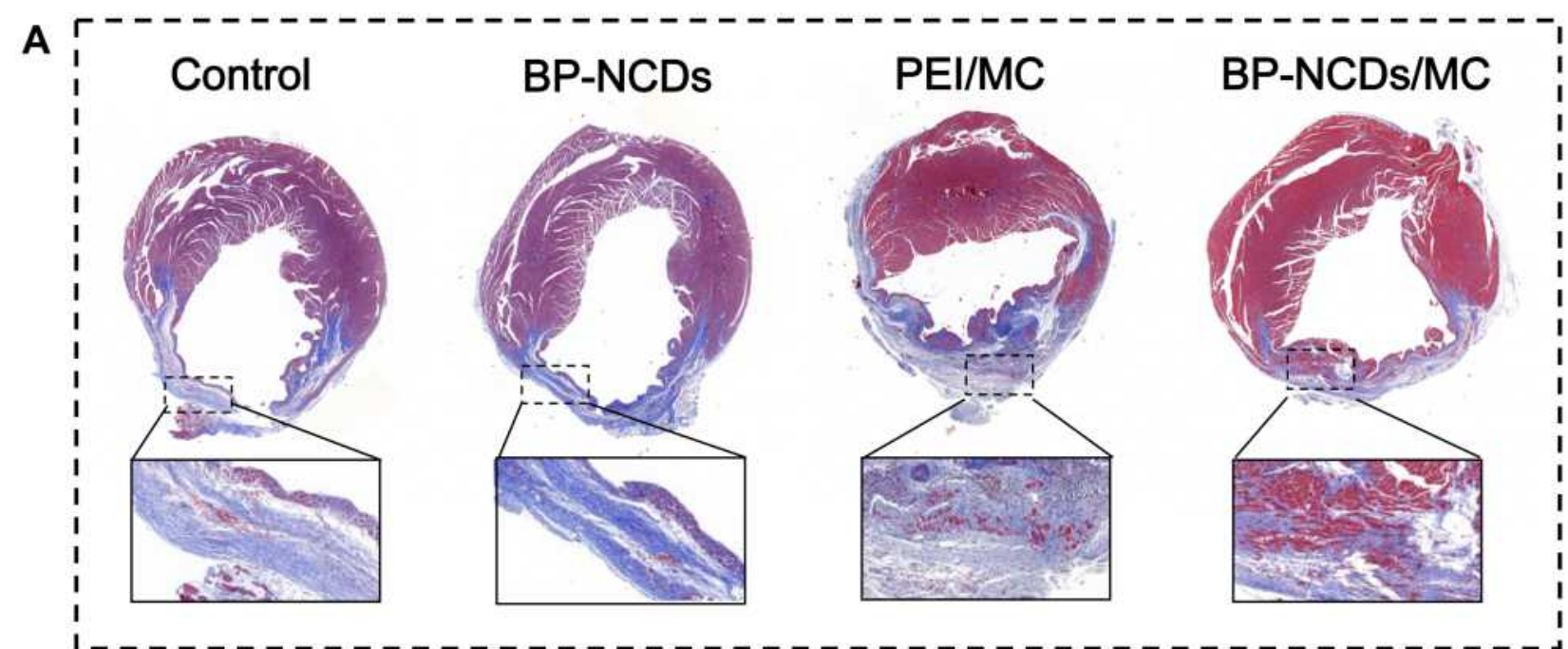

B

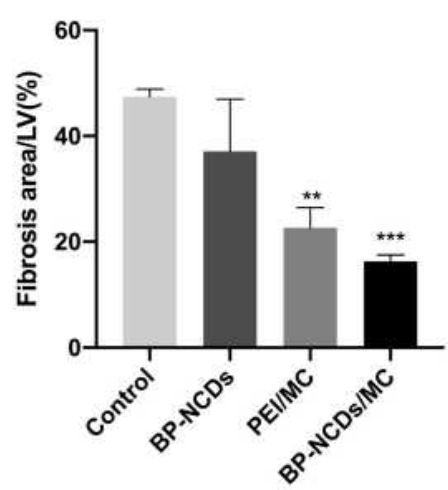

C

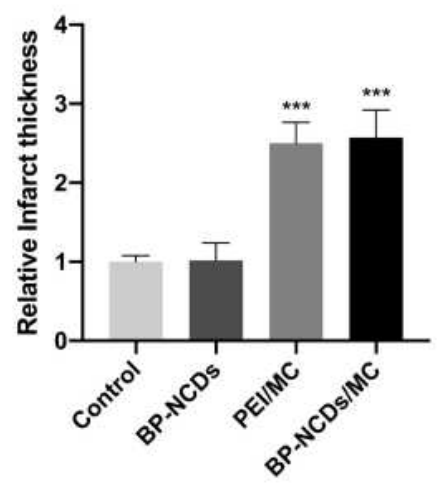

E
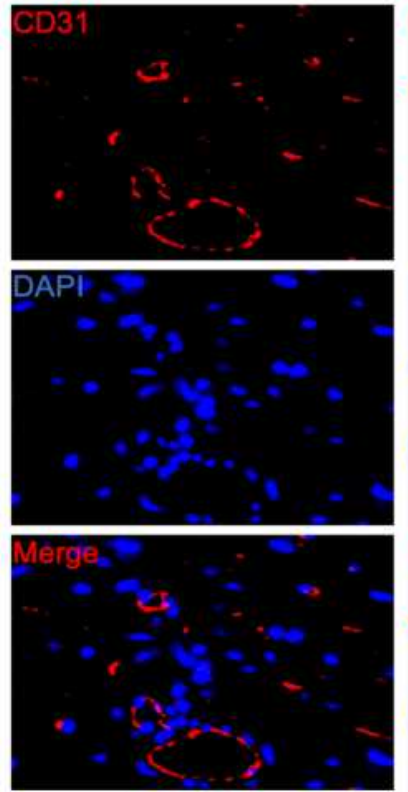

Control
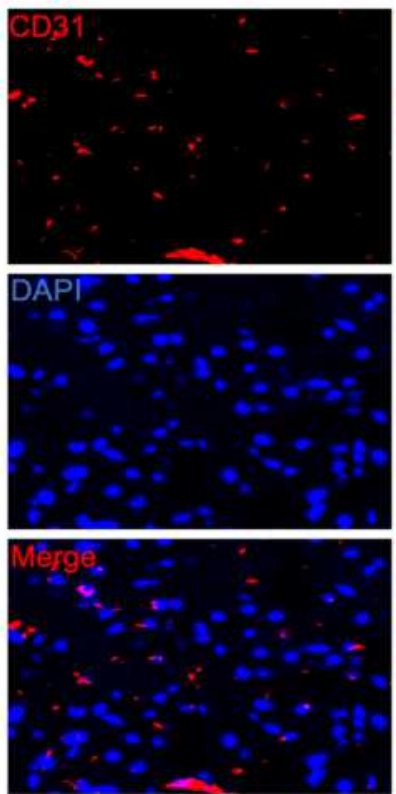

BP-NCDs
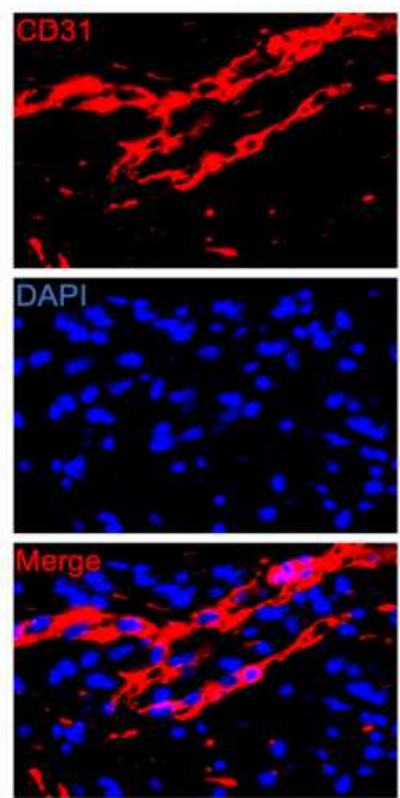

PEI/MC

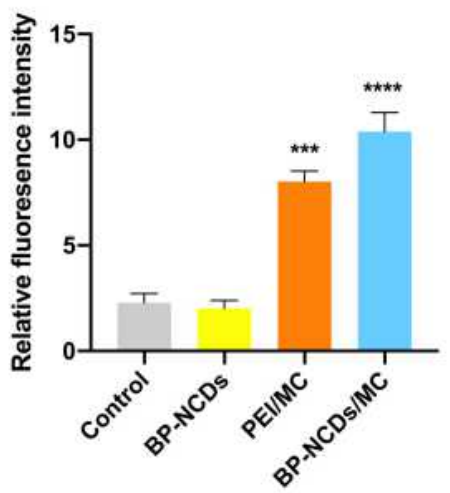

Figure 8 (A) Masson trichrome images showing scar (blue) and viable (red) tissues in cross sections post-surgery (Top Line). Magnified images showing the infarct area of MT image (Bottom Line). (B) Percentage of fibrosis area per left ventricular after coronary ligation and PBS, BP-NCDs, PEI/MC, or BP-NCDs/MC treatment. (C) Analysis of cardiac remodeling by quantification of the thickness of the ventricular wall in the infarct area. (D) Quantified fluorescence intensity of $C D 3 \mid$ expression. (E) Immunofluorescent staining for CD3I in PBS, BP-NCDs, PEI/MC, and BP-NCDs/MC injection (5 $\mu g$ miRNAs in $20 \mu \mathrm{L}$ BP-NCDs). The data represent mean \pm SEM; oneway ANOVA, *p $<0.05$, **p $<0.01$, ***p $<0.001$, ****p $<0.0001$. 


\section{Acknowledgments}

This work was supported by the National Natural Science Foundation of China (81873461).

\section{Disclosure}

The authors report no conflicts of interest.

\section{References}

1. Zhao D, Liu J, Wang M, et al. Epidemiology of cardiovascular disease in China: current features and implications. Nat Rev Cardiol. 2019;16(4):203-212. doi:10.1038/s41569-018-0119-4

2. Hausenloy DJ, Yellon DM. Myocardial ischemia-reperfusion injury: a neglected therapeutic target. J Clin Invest. 2013;123:92-100. doi:10.1136/heartjnl-2015-307855

3. Takahashi K, Tanabe K, Ohnuki M, et al. Induction of pluripotent stem cells from adult human fibroblasts by defined factors. Cell. 2007;131:861-872. doi:10.1016/j.cell.2007.11.019

4. Takahashi K, Yamanaka S. Induction of pluripotent stem cells from mouse embryonic and adult fibroblast cultures by defined factors Cell. 2006;126:663-676. doi:10.1016/j.cell.2006.07.024

5. Nelson TJ, Martinez-Fernandez A, Yamada S, et al. Repair of Acute myocardial infarction by human stemness factors induced pluripoten stem cells. Circulation. 2009;120:408-416. doi:10.1161/ CIRCULATIONAHA.109.865154

6. Mummery C. Induced pluripotent stem cells - a cautionary note. N Engl J Med. 2011;364:2160-2162. doi:10.1056/NEJMcibr1103052

7. Nishimori M, Yakushiji H, Mori M, et al. Tumorigenesis in cells derived from induced pluripotent stem cells. Cell. 2014;27:29-35. doi:10.1007/s13577-013-0078-3

8. Yamashita T, Kawai H, Tian F, et al. Tumorigenic development of induced pluripotent stem cells in ischemic mouse brain. Cell Transplant. 2011;20:883-892. doi:10.3727/096368910X539092

9. Srivastava D, Ivey KN. Potential of stem-cell-based therapies for heart disease. Nature. 2006;441:1097-1099. doi:10.1038/ nature04961

10. Passier R, van Laake LW, Mummery CL. Stem-cell-based therapy and lessons from the heart. Nature. 2008;453:322-329. doi:10.1038/ nature 07040

11. Ieda M, Fu JD, Delgado-Olguin P, et al. Direct reprogramming of fibroblasts into functional cardiomyocytes by defined factors. Cell. 2010;142:375-386. doi:10.1016/j.cell.2010.07.002

12. Qian L, Berry EC, Fu JD, et al. Reprogramming of mouse fibroblasts into cardiomyocyte-like cells in vitro. Nat Protoc. 2013;8:1204-1215. doi:10.1038/nprot.2013.067

13. Qian L, Huang Y, Spencer CI, et al. In vivo reprogramming of murine cardiac fibroblasts into induced cardiomyocytes. Nature. 2012;485:593-598. doi:10.1038/nature11044

14. Song K, Nam YJ, Luo X, et al. Heart repair by reprogramming non-myocytes with cardiac transcription factors. Nature. 2012;485:599-604. doi:10.1038/nature11139

15. Islas JF, Liu Y, Weng KC, et al. Transcription factors ETS2 and MESP1 transdifferentiate human dermal fibroblasts into cardiac progenitors. Proc Natl Acad Sci. 2012;109:13016-13021. doi:10.1073/pnas.1120299109

16. Mohamed TM, Stone NR, Berry EC, et al. chemical enhancement of in vitro and in vivo direct cardiac reprogramming. Circulation. 2017;135:978-995. doi:10.1161/CIRCULATIONAHA.116.024692

17. Zhao Y, Londono P, Cao Y, et al. High-efficiency reprogramming of fibroblasts into cardiomyocytes requires suppression of pro-fibrotic signalling. Nat Commun. 2015;6:8243. doi:10.1038/ncomms9243
18. Zhou H, Dickson ME, Kim MS, et al. Akt1/protein kinase B enhances transcriptional reprogramming of fibroblasts to functional cardiomyocytes. Proc Natl Acad Sci. 2015;112:11864-11869. doi:10.1073/pnas.1516237112

19. Dal-Pra S, Hodgkinson CP, Mirotsou M, et al. Demethylation of $\mathrm{H} 3 \mathrm{~K} 27$ is essential for the induction of direct cardiac reprogramming by miR combo. Circ Res. 2017;120:1403-1413. doi:10.1161/ CIRCRESAHA.116.308741

20. Liu Z, Chen O, Zheng M, et al. Re-patterning of H3K27me3, H3K4me3 and DNA methylation during fibroblast conversion into induced cardiomyocytes. Stem Cell Res. 2016;16:507-518. doi:10.1016/j.scr.2016.02.037

21. Muraoka N, Yamakawa H, Miyamoto K, et al. MiR-133 promotes cardiac reprogramming by directly repressing Snail and silencing fibroblast signatures. EMBO J. 2014;33:1565-1581. doi:10.15252/ embj.201387605

22. Jayawardena TM, Egemnazarov B, Finch EA, et al. MicroRNAmediated in vitro and in vivo direct reprogramming of cardiac fibroblasts to cardiomyocytes. Circ Res. 2012;110:1465-1473. doi:10.1161/CIRCRESAHA.112.269035

23. Yoo AS, Sun AX, Li L, et al. MicroRNA-mediated conversion of human fibroblasts to neurons. Nature. 2011;476:228-231. doi:10.1038/nature 10323

24. Miyoshi N, Ishii H, Nagano H, et al. Reprogramming of mouse and human cells to pluripotency using mature MicroRNAs. Cell Stem Cell. 2011;8:633-638. doi:10.1016/j.stem.2011.05.001

25. Maherali N, Ahfeldt T, Rigamonti A, et al. A high-efficiency system for the generation and study of human induced pluripotent stem cells. Cell Stem Cell. 2008;3:340-345. doi:10.1016/j.stem.2008.08.003

26. Okita K, Ichisaka T, Yamanaka S. Generation of germline-competent induced pluripotent stem cells. Nature. 2007;448:313-317. doi:10.1038/nature 05934

27. Carey BW, Markoulaki S, Hanna JV, et al. Reprogramming of murine and human somatic cells using a single polycistronic vector. Proc Natl Acad Sci. 2009;106:157-162. doi:10.1073/pnas.0811426106

28. Kim D, Kim CH, Moon JI, et al. Generation of human induced pluripotent stem cells by direct delivery of reprogramming proteins. Cell Stem Cell. 2009;4:472-476. doi:10.1016/j. stem.2009.05.005

29. Judson RL, Babiarz JE, Venere M, et al. Embryonic stem cellspecific microRNAs promote induced pluripotency. Nat Biotechnol. 2009;27:459-461. doi:10.1038/nbt.1535

30. Cao X, Deng W, Qu R, et al. Non-Viral Co-Delivery of the Four Yamanaka Factors for Generation of Human Induced Pluripotent Stem Cells via Calcium Phosphate Nanocomposite Particles. Adv Funct Mater. 2013;23:5403-5411. doi:10.1002/adfm.201203646

31. Mormone E, Sousa SD, Alexeeva V, et al. "Footprint-free" human induced pluripotent stem cell-derived astrocytes for in vivo cell-based therapy. Stem Cells Dev. 2014;23:2626-2636. doi:10.1089/ scd.2014.0151

32. Midoux P, Breuzard G, Gomez JP, et al. Polymer-based gene delivery: a current review on the uptake and intracellular trafficking of polyplexes. Curr Gene Ther. 2008;8:335-352. doi:10.2174/ 156652308786071014

33. Deng WW, Cao X, Wang M, et al. Efficient gene delivery to mesenchymal stem cells by an ethylenediamine-modified polysaccharide from mulberry leaves. Small. 2012;8:441-451. doi:10.1002/ smll.201101554

34. Das P, Bhattacharyy SK, Banerjic P, et al. Acoustic cavitation assisted synthesis and characterization of photoluminescent carbon quantum dots for biological applications and their future prospective. NanoStruct Nano Objects. 2021;25:100641. doi:10.1016/j. nanoso.2020.100641 
35. Bhattacharyya S, Dule M, Paul R, et al. Carbon dot cross-linked gelatin nanocomposite hydrogel for $\mathrm{pH}-\mathrm{Sensing}$ and $\mathrm{pH}$-responsive drug delivery. ACS Biomater Sci Eng. 2020;6(10):5662-5674. doi:10.1021/acsbiomaterials.0c00982

36. Essex S, Navarro G, Sabhachandani P, et al. Phospholipid-modified PEI-based nanocarriers for in vivo siRNA therapeutics against multidrug-resistant tumors. Gene Ther. 2015;22:257-266. doi:10.1038/gt.2014.97

37. Xia C, Zhu S, Feng T, et al. Evolution and synthesis of carbon dots: from carbon dots to carbonized polymer dots. Adv Sci. 2019;23:1901316. doi:10.1002/advs.201901316

38. Chung S, Revia RA, Zhang M. Graphene quantum dots and their applications in bioimaging, biosensing, and therapy. Adv Mater. 2019;12:1904362. doi:10.1002/adma.201904362

39. Yang S, Wang $\mathrm{X}$, He $\mathrm{P}$, et al. Carbon quantum dots and their applications. Chem Soc Rev. 2015;44:362-381. doi:10.1002/ smll.202004867

40. Liu C, Zhang P, Zhan XY, et al. Nano-carrier for gene delivery and bioimaging based on carbon dots with PEI-passivation enhanced fluorescence. Biomaterials. 2012;33:3604. doi:10.1016/j. biomaterials.2012.01.052

41. Pierrata P, Wang R, Kereselidzea D, et al. Biomaterials. 2015; 51: 290. doi:10.1016/j.biomaterials.2015.02.017

42. Kim S, Choi Y, Park G, et al. Highly efficient gene silencing and bioimaging based on fluorescent carbon dots in vitro and in vivo. Nano Res. 2017;10(2):503-519. doi:10.1007/s12274-016-1309-1

43. Verma A, Stellacci F. Effect of surface properties on nanoparticlecell interactions. Small. 2010;6:12-21. doi:10.1002/smll.200901158
44. Nekoueian K, Amiri M, Sillanpää M, et al. Carbon-based quantum particles: an electroanalytical and biomedical perspective. Chem Soc Rev. 2019;48:4281-4316. doi:10.1039/c8cs00445e

45. Chen J, Wang Q, Zhou J, et al. Porphyra polysaccharide-derived carbon dots for non-viral co-delivery of different gene combinations and neuronal differentiation of ectodermal mesenchymal stem cells. Nanoscale. 2017;9:10820-10831. doi:10.1039/c7nr03327c

46. Chang Y, Lee E, Kim J, et al. Efficient in vivo direct conversion of fibroblasts into cardiomyocytes using a nanoparticle-based gene carrier. Biomaterials. 2019;192:500-509. doi:10.1016/j. biomaterials.2018.11.034

47. Shu M, Gao F, Yu C, et al. Dual-targeted therapy in HER2-positive breast cancer cells with the combination of carbon dots/HER3 siRNA and trastuzumab. Nanotechnology. 2020;31:335102. doi:10.1088/ $1361-6528 / a b 8 a 8 a$

48. Li XH, Li Q, Jiang L, et al. Generation of functional human cardiac progenitor cells by high-efficiency protein transduction. Stem Cells Transl Med. 2015;4:1415-1424. doi:10.5966/sctm.2015-0136

49. Liu Z, Wang L, Welch JD, et al. Single-cell transcriptomics reconstructs fate conversion from fibroblast to cardiomyocyte. Nature. 2017;551:100-104. doi:10.1038/nature24454

50. Lalit PA, Salick MR, Nelson DO, et al. Lineage reprogramming of fibroblasts into proliferative induced cardiac progenitor cells by defined factors. Cell Stem Cell. 2016;18:354-367. doi:10.1016/j. stem.2015.12.001
International Journal of Nanomedicine

\section{Publish your work in this journal}

The International Journal of Nanomedicine is an international, peerreviewed journal focusing on the application of nanotechnology in diagnostics, therapeutics, and drug delivery systems throughout the biomedical field. This journal is indexed on PubMed Central, MedLine, CAS, SciSearch ${ }^{\circledR}$, Current Contents ${ }^{\mathbb{R}} /$ Clinical Medicine,

\section{Dovepress}

Journal Citation Reports/Science Edition, EMBase, Scopus and the Elsevier Bibliographic databases. The manuscript management system is completely online and includes a very quick and fair peer-review system, which is all easy to use. Visit http://www.dovepress.com/ testimonials.php to read real quotes from published authors. 